\title{
Use of Therapeutic Laser for Prevention and Treatment of Oral Mucositis
}

\author{
Vivian Youssef KHOURI \\ Ana Beatriz Pereira Lima STRACIERI \\ Maria Carolina RODRIGUES \\ Daniela Aparecida de MORAES \\ Fabiano PIERONI \\ Belinda Pinto SIMÕES \\ Júlio César VOLTARELLI
}

University Hospital, School of Medicine of Ribeirão Preto, University of São Paulo, Ribeirão Preto, SP, Brazil

\begin{abstract}
Oral mucositis (OM) affects patients who are submitted to hematopoietic stem cell transplantation (HSCT) due to high doses of chemotherapy and/or radiotherapy. The purpose of this investigation was to perform a comparative study of the frequency and evolution of OM among patients subjected to therapeutic laser and to the conventional therapy (use of mouthwash called "Mucositis Formula"). The patients were subjected to a myeloablative conditioning regimen before the allogeneic HSCT. Twenty-two patients were selected and divided into 2 groups: group I was irradiated with InGaAlP laser $(660 \mathrm{~nm})$ and GaAlAs laser $(780 \mathrm{~nm}), 25 \mathrm{~mW}$ potency, $6.3 \mathrm{~J} /$ $\mathrm{cm}^{2}$ dose, in 10-s irradiation time, followed to conventional treatment; group II was subjected only to the conventional treatment. Both World Health Organization (WHO) scale and the Oral Mucositis Assessment Scale (OMAS) were used to evaluate the results. Data were analyzed by the non-parametric Wilcoxon test, with $\mathrm{p}<0.05$ considered as statistically significant. Group I presented a lower frequency of OM ( $\mathrm{p}=0.02)$ and lower mean scores, according to WHO and OMAS scales ( $<<0.01$ and $\mathrm{p}=0.01$, respectively). In conclusion, laser reduced the frequency and severity of OM, suggesting that therapeutic laser can be used both as a new form of prevention and treatment of OM.
\end{abstract}

Key Words: oral mucositis, chemotherapy, radiotherapy, allogeneic hematopoietic stem cell transplantation, therapeutic laser.

\section{INTRODUCTION}

Hematopoietic stem cell transplantation (HSCT) or bone marrow transplantation is used as a therapeutic modality for malignant and non-malignant hematological diseases, severe immunodeficiences and bone marrow aplasia (1). HSCT requires the application of a conditioning regimen leading to myeloablation in order to create a space in the bone marrow of the recipient (2). Immunosuppression and destruction of neoplastic cells are other effects of high doses of chemotherapeutic drugs in combination or not with whole body radiotherapy.

Oral mucositis (OM) is a common complication of cytotoxic chemotherapy and radiotherapy (3). This condition affects the mucosa of the gastrointestinal tract and especially the mucosa of the oral cavity and the oropharynx. It mainly affects patients subjected to aggressive myeloablative chemotherapy associated or not with radiotherapy, procedures that are also used in conditioning regimens for HCST $(4,5)$. The incidence of mucositis in these patients is approximately 80 to $100 \%$ (6). Clinically, mucositis starts in an asymptomatic manner, followed by the presence of erythema, burning complaints and increased sensitivity to hot and spicy foods. The erythema may progress to areas of desquamation, followed by the appearance of ulcers associated with dysphagia and reduced oral ingestion, with a series of clinical consequences that affect the quality of life of the patients (6).

In view of the complexity of this toxicity, there is no standard of prevention or treatment, with a diversified management of OM. In our Bone Marrow 
Transplant Unit (BMTU) of the University Hospital of the School of Medicine of Ribeirão Preto, University of São Paulo (UHSMRP/USP), Brazil, a mouthwash known as "Mucositis Formula" has been used for the treatment of clinical manifestations of $\mathrm{OM}$, such as pain, erythema and ulceration. This oral rinse was developed at the UHSMRP/USP, Brazil, and is a combination of antiinflammatory (benzidamine), antifungal (nistatin) and anesthetic agents (neututocain) and distilled water.

Rubenstein et al. (7) described experimental therapies using for the prevention or treatment of OM such as cryotherapy, benzidamine and palifermin, which reduced the severity of mucositis. According to Campos et al. (8), laser therapy offers as a new approach for the prevention and treatment of $\mathrm{OM}$, reducing the pain and stimulating the salivary glands.

In view of the small number of studies on the use of therapeutic laser for the prevention and treatment of OM, this study compared the frequency and course of OM between groups of patients managed with therapeutic laser and conventional treatment ("Mucositis Formula").

\section{MATERIAL AND METHODS}

The study was conducted at the BMTU of the UHSMRP/USP, Ribeirão Preto, SP, Brazil, from March 2004 to September 2006, with the participation of 22 patients subjected to allogeneic HSCT. The study was approved by the local Research Ethics Committee (Protocol \#1534/2004) and all subjects gave written informed consent to participate in the study.

The patients were randomized into 2 groups according to the order of hospitalization. Demographic characteristics of both groups are shown in Table 1.

The conditioning regimen (high dose chemotherapy) was given to the 2 groups before stem cell infusion. In group I, 2 patients received cyclophosphamide (D-5 to D-2, $50 \mathrm{mg} / \mathrm{kg}$ ), 6 patients received busulfan (D-7 to D-4, $1 \mathrm{mg} / \mathrm{kg}$ ) with cyclophosphamide (D-3 to $\mathrm{D}-2,60 \mathrm{mg} / \mathrm{kg}$ ), 3 patients received busulfan (D-6 to D-3, $1 \mathrm{mg} / \mathrm{kg}$ ) with fludarabine (D-6 to D-2, $30 \mathrm{mg} /$ $\mathrm{m}^{2}$ ) and 1 patient received total body irradiation (D-6 to D-4, 990 cGy total) and cyclophosphamide (D-3 to $\mathrm{D}-2,60 \mathrm{mg} / \mathrm{kg}$ ).

In group II, 1 patient received busulfan (D-7 to D-4, $1 \mathrm{mg} / \mathrm{kg}$ ) with cyclophosphamide (D-3 to D-2, 60 $\mathrm{mg} / \mathrm{kg}$ ), 2 patients received busulfan (D-6 to D-3, $1 \mathrm{mg}$ / $\mathrm{kg}$ ) with fludarabine (D-6 to D-2, $30 \mathrm{mg} / \mathrm{m}^{2}$ ), 4 patients received total body irradiation (D-6 to D-4, $990 \mathrm{cGy}$ total) and cyclophosphamide (D-3 to D-2, $60 \mathrm{mg} / \mathrm{kg} /$ ) and 1 patient received fludarabine $\left(30 \mathrm{mg} / \mathrm{m}^{2}\right) /$ citarabine $\left(2000 \mathrm{mg} / \mathrm{m}^{2}\right) /$ mitoxantrone $\left(10 \mathrm{mg} / \mathrm{m}^{2}\right)$ from $\mathrm{D}-10$ to D-7 and melfalan (D-3 to D-2, $70 \mathrm{mg} / \mathrm{m}^{2}$ ).

All patients were subjected to treatment with methotrexate in combination with cyclosporine after transplantation for prevention of graft-versus-host disease.

Inclusion criteria were: 12 years of age or older, both genders, hematologic or onco-hematologic disease, myeloablative conditioning regimen, and allogeneic hematopoietic stem cell transplantation. Exclusion criteria were: autoimmune disease, non-myeloablative conditioning regimen, and haploidentical or autologous hematopoietic stem cell transplantation. Groups I and II were subjected to different protocols for the prevention and treatment of OM.

The prevention phase for both groups started on the first day of conditioning and lasted until the initial clinical manifestation of mucositis in the oral cavity. The standard protocol for oral hygiene consisted of using soft-bristle toothbrushes and rinsing with $0.9 \%$ saline 4 times a day after meals, followed by rinsing with a benzidamine solution at the same frequency. In the beginning of 2006, the benzidamine solution was replaced by an alcohol-free $0.12 \%$ chlorhexidine

Table 1. Demographic and clinical characteristics of the patients.

\begin{tabular}{lcc}
\hline & $\begin{array}{c}\text { Group I } \\
\text { Laser therapy } \\
(\mathrm{n}=12)\end{array}$ & $\begin{array}{c}\text { Group II } \\
\text { Mucositis Formula } \\
(\mathrm{n}=10)\end{array}$ \\
\hline Mean age (years) & 32.7 & 27.5 \\
Gender & 10 & \\
Male & 2 & 3 \\
Female & 5 & 3 \\
Diagnosis & 1 & 2 \\
Acute myeloid leukemia & 3 & 2 \\
Acute lymphoid leukemia & 2 & 2 \\
Chronic myeloid leukemia & 1 & 1 \\
Severe aplastic anemia & & \\
Myelodysplastic syndrome & & \\
\hline
\end{tabular}


gluconate solution.

The treatment phase for both groups started with the initial clinical manifestations of mucositis (e.g.: pain, edema, erythema) with follow-up until D+15 after transplantation, and consisting of the combination of the standard oral hygiene protocol with the use of the "Mucositis Formula" mouthwash. The composition of this rinse is: $0.15 \mathrm{~g}$ benzidamine, $1.13 \mathrm{~g}$ nistatin, $2 \mathrm{~g}$ neututocain and $10 \mathrm{~mL}$ distilled water. Benzidamine is an antiinflammatory agent that can reduce the production of pro-inflammatory cytokines and free radicals. Nistatin is a topical antifungal agent used for the treatment of oral candidiasis, the main opportunistic infection related to OM, and neututocain (an anesthetic) is used for pain relief. The difference between these 2 protocols was the inclusion of laser therapy both during the prevention and the treatment phase in group I.

Two scales were used for evaluation of OM: World Health Organization (WHO) Oral Toxicity Scale and Oral Mucositis Assessment Scale (OMAS). In the WHO scale, WHO 0 is defined no abnormality, WHO 1 is erythema requiring no treatment, WHO 2 is presence of pain requiring no analgesics, difficulty in feeding, WHO 3 is ulceration, pain requiring analgesics, feeding is impossible and WHO 4 is necrosis, total parenteral nutrition.

The OMAS scale measures ulceration and erythema. The assessment for ulceration in each site was scored from 0-3, with 0 representing no clinical lesion, 1 representing an ulcer $<1 \mathrm{~cm}^{2}, 2$ representing an ulcer of $1-3 \mathrm{~cm}^{2}$, and 3 representing an ulcer $>3 \mathrm{~cm}^{2}$. The erythema was scored between $0-2$, with 0 representing no erythema, 1 representing mild to moderate and 2 representing severe erythema. The sites of the oral mucosa evaluated with the OMAS scale were: upper and lower lips (vermilion and mucosa), bilateral jugal mucosa, floor of the mouth, lateral tongue surface on both sides, and ventral surface of the tongue, to which therapeutic laser was applied in group I. According to the OMAS criteria, the OMAS score $=2.5 \times\left[\left(\sum \mathrm{ui} / 3 \mathrm{nu}\right)\right.$ $\left.+\left(\sum \mathrm{ei} / 2 \mathrm{ne}\right)\right]$ was applied, with values between 0 and 5 . $\sum u i$ is the total sum of ulceration, $n u$ corresponds to the number of areas with ulceration, $\sum e i$ is the total sum of erythema, and ne corresponds to the number of areas with erythema, according to Sonis et al. (19).

After discharge from the wards, a specific questionnaire about laser therapy was applied to group I to check if they had any lesion, oral pain, swallow pain and improvement after laser, without persuade results. The study was not blinded because group II was subjected only to the conventional treatment and not to sham laser.

A low-intensity laser device (Twin Laser; MM Optics Ltda., São Carlos, SP, Brazil) purchased by our BMTU in 2003 was used in this study. The present study differed from the studies reported in the literature in that we compared the effect of laser therapy to that of conventional therapy. Several irradiation parameters were studied in order to determine the most adequate parameter settings to be used in the study. Two types of laser with the following diodes were used: indium gallium aluminum phosphide (InGaAlP) with $660 \mathrm{~nm}$ wavelength and gallium aluminum arsenide (GaAlAs) with $780 \mathrm{~nm}$ wavelength. The first diode emits a visible red laser, has lower penetration into biological tissue and is indicated for tissue repair, while the second diode emits infrared laser, has greater penetration capacity and it is indicated for analgesia. The laser applications were performed daily in the morning, once a day, and the 2 lasers were applied on alternate days using the same irradiation parameters: $25 \mathrm{~mW}$ output power, 10 -s irradiation time and $6.3 \mathrm{~J} / \mathrm{cm}^{2}$ dose per site and with direct contact with the mucosa.

The patients performed oral hygiene before the applications. The patients and the operator (VYK) wore protection eyeglasses during the procedure, which was carried out by the bedside on the ward, with the patient being isolated. Before the irradiations, the active tips of the pens were disinfected with $70 \%$ alcohol and covered with PVC film to avoid cross-contamination and at the end the PVC cover was discarded and the tip was disinfected again. The applications were performed up to $\mathrm{D}+15$, coinciding or not with engraftment of hematopoietic stem cells. If engraftment was observed before this day, the irradiations were stopped in order not to impair the study.

Data were analyzed by the non-parametric Wilcoxon test for 2 independent samples, with the level of significance set at $\mathrm{p}<0.05$. The exact version of the Wilcoxon test was used. Graphs were constructed using the Microsoft Office Excel 2003 and GraphPad Prisma 4 and 5 softwares (GraphPad Software, Inc., San Diego, CA, USA).

\section{RESULTS}

The results obtained with the application of the 
WHO scale are presented in Figure 1. Comparison of the course of OM between patients of groups I and II, showed that group I presented a lower frequency of OM (Fig. 1) and the difference between groups was statistically significant ( $\mathrm{p}=0.02$ ).

The mean grade of mucositis observed in group I was $1.75 \pm 0.45$, whereas group II presented a mean of $2.45 \pm 0.93$. The difference between groups was statistically significant $(\mathrm{p}<0.01)$, according to the WHO scale. Regarding the size of ulcerations in the oral cavity as a whole, group I presenting fewer sites with ulcerations/ pseudomembranes and a smaller number of lesions compared to group II (Fig. 2).

Using the OMAS scale, the mean frequencies of OM observed in groups I and II were 7.0 \pm 3.2 and $14.0 \pm 8.3$, respectively, with statistically significant difference $(p=0.01)$ between the groups. Figure 3 illustrates the maximum OM values (ulceration + erythema) according to the OMAS score. It can be seen that the same values were obtained when laser therapy was used and the results were statistically significant $(\mathrm{p}=0.026)$. There was no clinical difference in the manifestation of erythema between groups, according to the OMAS scale. In group I, 10 patients presented mild/moderate erythema ( $83.3 \%$ ) and mild/moderate to severe erythema occurred in 2 patients (16.6\%), while in group II, 8 patients presented mild/moderate erythema ( $80 \%)$, severe erythema occurred in 1 patient $(10 \%)$ and only 1 patient this group did not present erythema (10\%).

Regarding the answers to the questionnaire applied to group I, $50 \%$ of the patients reported fewer lesions, $10 \%$ more lesions, $40 \%$ did not show any lesions,

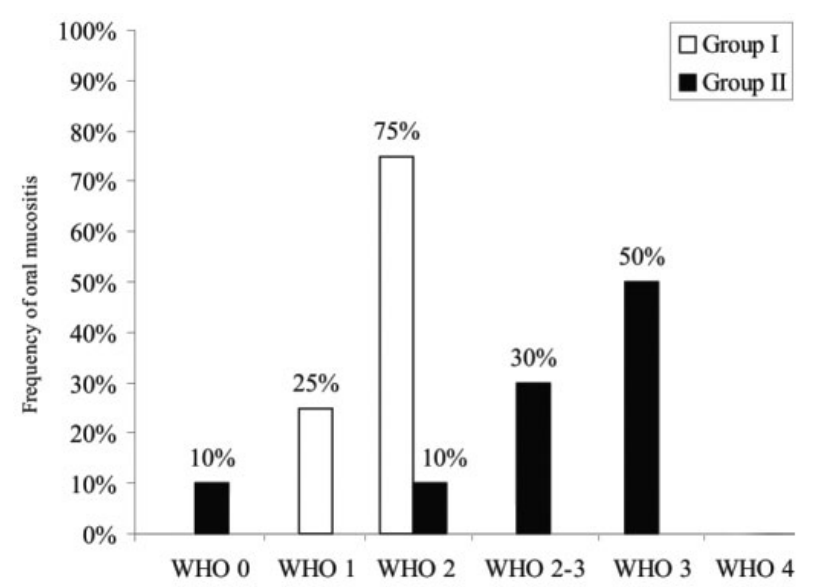

Figure 1. Frequency of oral mucositis in groups I and II $(p=0.02)$.
$75 \%$ reported not requiring analgesics for oral pain, $25 \%$ reported use the analgesics to oral pain, $100 \%$ pain to swallowing, $100 \%$ improvement after laser applications.

\section{DISCUSSION}

$\mathrm{OM}$ is the most common and uncomfortable adverse effect in patients subjected to high doses of chemotherapy or radiotherapy and in patients subjected to HSCT. The clinical consequences are presence of pain and difficulty in feeding, swallowing and speaking (17).

Several therapies for the prevention and treatment of OM have been tested, The most recent one was the use of palifermin (human recombinant keratinocyte growth factor, KGF), which stimulates epithelial cells. The results were significant, with reduction of both the incidence and the duration of severe OM, and improvement of pain (5).

Some therapeutic agents have shown insufficient evidence in the literature regarding the prevention and/ or treatment of mucositis, such as chlorhexidine (prevention), aminofostine (treatment), and chamomile (prevention and treatment), as reported by Rubenstein et al. (7).

Several studies have shown the benefits of therapeutic laser to prevent and treat oral mucositis and has several biological effects such as pain relief, antiinflammatory effects and acceleration of the regeneration of damaged tissues (10). Thus, laser therapy is a noninvasive technique that promotes pain relief and reduce the severity of oral mucositis in patients subjected HSCT, as reported by Jaguar et al. (20).

The first studies in patients involved the use of helium-neon (He-Ne) laser with a wavelength of 632.8

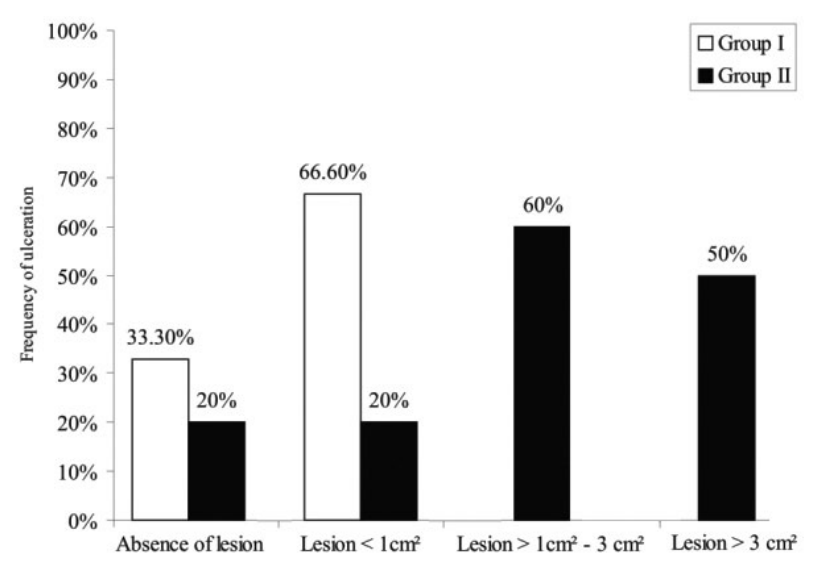

Figure 2. Size of the lesions in groups I and II. 
$\mathrm{nm}$ (9), while current studies use several types of diodes such as the InGaAIP laser of $660 \mathrm{~nm}$ (18), the InGaAlP laser of $685 \mathrm{~nm}$ (14) and $660 \mathrm{~nm}$ (12), the GaAlAs laser of $830 \mathrm{~nm}(16)$.

Eduardo et al. (18) reported the use of a InGaAIP laser $(660 \mathrm{~nm})$ with $40 \mathrm{~mW}$ and energy density of $4 \mathrm{~J} /$ $\mathrm{cm}^{2}$ (for prevention of ulceration) or $6 \mathrm{~J} / \mathrm{cm}^{2}$ (for treatment of confirmed ulcerations) in 30 patients undergoing autologous $(63.3 \%)$ or allogeneic $(36.7 \%)$ HSCT. The results showed improvement of OM after laser therapy. According to Lopes et al. (14), laser treatment at several sites in the oral cavity during chemotherapy and radiotherapy reduces the severity and duration of OM, oral pain and xerostomia. Antunes et al. (12) investigated the use InGAlP laser $\left(660 \mathrm{~nm}\right.$ ) with $50 \mathrm{~mW}$ and $4 \mathrm{~J} / \mathrm{cm}^{2}$ for prevention and reduction of $\mathrm{OM}$ in patients subjected to autologous or allogeneic HSCT. The WHO and OMAS scales were used simultaneously for the evaluation of mucositis in the oral cavity. The result was a reduction of the progression of the OM with better pain control with laser therapy.

The use of laser therapy can be a powerful instrument to reduce of mucostis in patients undergoing chemotherapy. In a pilot clinical study (13), the pediatric patients were randomized to group I (prophylactic laser irradiation), group II (placebo laser irradiation) and group III (therapeutic laser irradiation). The AsGaAl

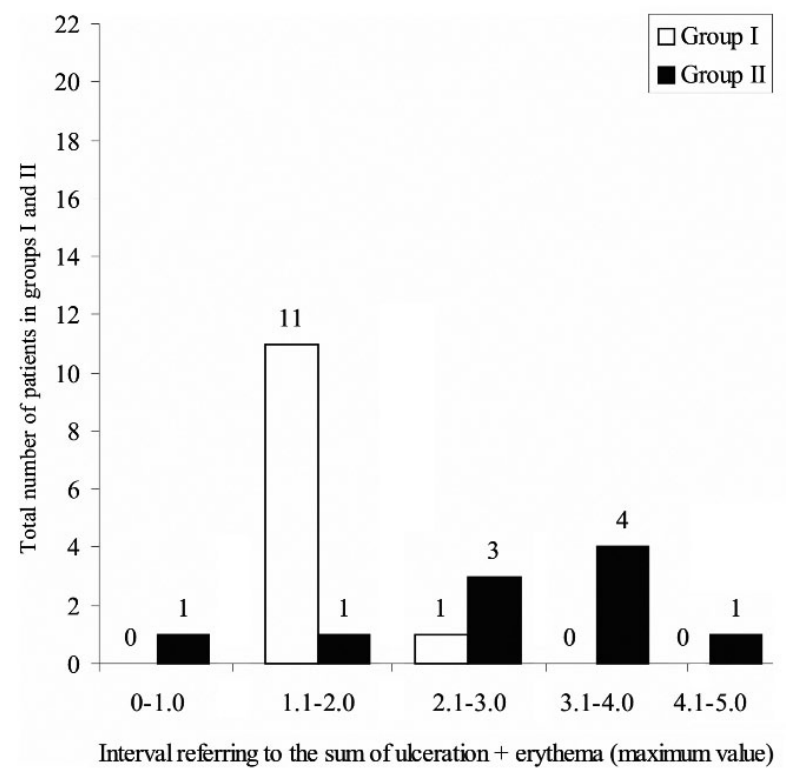

Figure 3. Evaluation of the severity of oral mucositis according to the OMAS score $(\mathrm{p}=0.026)$. laser $(685 \mathrm{~nm})$ was used, $35 \mathrm{~mW}, 2 \mathrm{~J} / \mathrm{cm}^{2}$ per point of application, and OM was graded according to National Institute's Common Toxicity Criteria. The use of laser for prophylaxis showed reduction of mucositis in group 1 [8 patients (73\%) presented OM grade 0$]$ when compared to group 2 [2 patients $(27 \%)$ had no OM]. The use of laser for treatment in group III was done when $\mathrm{OM}$ was diagnosed and these patients noted pain relief and without oral mucositis worsening after laser.

In the present study, the group I was irradiated with AlGaInP $(660 \mathrm{~nm})$ and GaAlAs $(780 \mathrm{~nm})$ lasers with $25 \mathrm{~mW}$ power, $6.3 \mathrm{~J} / \mathrm{cm}^{2}$ dose, in $10 \mathrm{~s}$ time. The 2 lasers were used alternately from the start of the conditioning regimen until the $\mathrm{D}+15$ post-transplantation. The WHO and OMAS scales were used for evaluating OM, according to Antunes et al. (12).

Comparison of the course of OM between the use to therapeutic laser (group I) and "Mucositis Formula" (group II) showed that group I presented a lower frequency and severity of OM, according to WHO scale. With the application of the OMAS scale, $33.30 \%$ patients did not show any lesions and $66.60 \%$ showed lesions of $<1 \mathrm{~cm}^{2}$, whereas group II developed a major frequency of $\mathrm{OM}$ and more extensive lesions.

The use of therapeutic laser in the present study showed positive outcomes and the efficacy of laser to prevent and treat OM in patients subjected to HSCT, chemotherapy and radiotherapy, in accordance with data found in the literature $(8,11-16,18,20)$ and the results were similar to those obtained by Antunes et al. (12). The outcomes of the present study add to the evidence that therapeutic laser can be an effective option for the prevention and treatment of $\mathrm{OM}$ in patients subjected to HSCT with the absence of adverse effects or discomfort, as suggested by other authors $(11,13)$.

However, few patients have been treated and most studies are not randomized. Thus, further studies with therapeutic laser on patients susceptible to OM are needed, preferably using a larger population. Nevertheless, in order to avoid conflicting results, it is necessary to standardize irradiation protocols for patients subjected to high doses of chemotherapy, followed or not by BMT. The availability of specialized professionals qualified for the use of laser according to safety guidelines is of paramount importance.

In conclusion, in the present study, patients treated with low-level laser therapy (group I) presented a lower frequency and progression of OM than those 
that received conventional therapy with the "Mucositis Formula" (group II). The inclusion of laser therapy also reduced the number and severity of the lesions in patients of group I with established OM compared to group II. The present results add important evidence regarding the use of laser therapy as a standard method for the prevention and treatment of OM after allogeneic HSCT.

\section{RESUMO}

A mucosite oral (MO) afeta pacientes que são submetidos ao transplante de células-tronco hematopoéticas (TCTH) devido as altas doses de quimioterapia e/ou radioterapia. A proposta desta investigação foi realizar um estudo comparativo da freqüência e a evolução da MO entre os pacientes submetidos ao laser terapêutico e da terapia convencional (uso de solução de bochecho chamada "Fórmula para Mucosite").Os pacientes foram submetidos ao regime de condicionamento mieloablativo antes da realização do TCTH alogênico.Vinte e dois pacientes foram selecionados e divididos em 2 grupos: grupo I foi irradiado com laser AlGaInP (660 nm) e laser GaAlAs $(780 \mathrm{~nm})$, potência de $25 \mathrm{~mW}$, dose de $6,3 \mathrm{~J} / \mathrm{cm}^{2}$, tempo $10 \mathrm{~s}$, seguido do tratamento convencional; grupo II submetido apenas ao tratamento convencional. Ambas as escalas da World Health Organization (WHO) e Oral Mucositis Assessment Scales (OMAS) foram utilizadas para avaliar os resultados. Os dados foram analizados pelo teste não-paramétrico de Wilcoxon, com $\mathrm{p}<0,05$ considerado estatisticamente significante. $\mathrm{O}$ grupo I apresentou menor frequência de MO ( $p=0,02)$ e menor média de acordo com as escalas WHO e OMAS ( $p<0,01$ e p=0,01, respectivamente). Em conclusão, o laser reduziu a frequência e gravidade da MO, sugerindo que o laser terapêutico pode ser usado para ambos como uma nova forma de prevenção e tratamento da MO.

\section{ACKNOWLEDGEMENTS}

The authors would like to thank Dr. Marina Coutinho, Dr. George Maurício Navarro Barros and Dr. Renato Luiz Guerino Cunha for their valuable help.

\section{REFERENCES}

1. Holowiecki J. Indications for hematopoietic stem cell transplantation. Pol Arch Med Wewn 2008;118:658-663.

2. Paton EJA, Coutinho MA, Voltarelli JC. Diagnosis and treatment of acute complications of hematopoietic stem cell transplantation. Medicine 2000;33:264-277.

3. Corti L, Chiarion-Sileni V, Aversa S, Ponzoni A, D'Arcais R, Pagnutti S, et al.. Treatment of chemotherapy-induced oral mucositis with light-emitting diode. Photomed Laser Surg 2006;24:207-213.

4. Sonis ST. The pathobiology of mucositis. Nature Rev Cancer 2004;4:277-284.
5. Spielberger RT. Kepivance ${ }^{\mathrm{TM}}$ : a breakthrough for oral mucositis associated with mieloablative hematopoietic stem cell transplantation. Center Int Blood Marrow Transplant Res 2005;11:1-12.

6. Massacesi C. Cancers therapy-induced oral mucositis: a comprehensive review. Oncol 2005;2:1-12.

7. Rubenstein EB, Peterson DE, Schubert M, Keefe D, Mcguire D, Epstein J, et al.. Clinical practice guidelines for the prevention and treatment of cancer therapy-induced oral and gastrointestinal mucositis. Cancer 2004;100:2026-2046.

8. Campos L, Simões A, Sá HRN, Eduardo CP. Improvement in quality of life of an oncological patient by laser phototherapy: a case report. Photomed Laser Surg 2008:1-4.

9. Bensadoun RJ, Ciais G. Radiation-and chemotherapy-induced mucositis in oncology: results of multicenter phase III studies. J Oral Laser App 2002;2:115-120.

10. Moriyama Y, Moriyama EH, Blackmore K, Akens M, Lilge L. In vivo study of the inflammatory modulating effects of low-level laser therapy on iNOS expression using bioluminescence imaging. Photochem and Photobiol 2005;81:1351-1355.

11. Genot-Klastersky MT, Klastersky J, Awada F, Awada A, Crombez P, Martinez D, et al.. The use of low-energy laser (LEL) for the prevention of chemotherapy and/or radiotherapy induced oral mucositis in cancer patients: results from two prospective studies. Supp Care Cancer 2008;16:1381-1387.

12. Antunes HS, Azevedo AM, Bouzas LFS, Adão CE, Pinheiro CT, Mayhe R, et al.. Low power laser in the prevention of induced oral mucositis in bone marrow transplantation patients: a randomized trial. Blood 2006:1-22.

13. Abramoff MMF, Lopes NNF, Lopes LA, Dib LL, Guilherme A, Caran EM, et al.. Low-level laser therapy in the prevention and treatment of chemotherapy-induced oral mucositis in young patients. Photomed Laser Surg 2008;26:394-400.

14. Lopes C, MAS JRI, Zângaro RA. Low level laser therapy in the prevention of radiotherapy-induced xerostomia and oral mucositis. Radiol Bras 2006;39:131-136.

15. Maiya GA, Sagar MS, Fernandes D. Effect of low level heliumneon $(\mathrm{He}-\mathrm{Ne})$ laser therapy in the prevention \& treatment of radiation induced mucositis in head \& neck cancer patients. Indian J Med Res 2006;124:399-402.

16. Nes AG, Posso MBS. Patients with moderate chemotherapyinduced mucositis: pain therapy using low intensity lasers. Int Nurs Rev 2005;52:68-72.

17. Scully C, Sonis S, Diz PD. Mucosal diseases series: oral mucositis. Oral Dis 2006;12:229-241.

18. Eduardo FP, Bezinelli L, Luiz AC, Correa L, Vogel C, Eduardo CP. Severity of oral mucositis in patients undergoing hematopoietic cell transplantation phototherapy protocol: a survey of 30 patients. Photomed Laser Surg 2008;26:1-8.

19. Sonis ST, Eilers JP, Epstein JB, Leveque FG, Liggett JR, Mulagha MT, et al.. Validation of a new scoring system for the assessment of clinical trial research of oral mucositis induced by radiation or chemotherapy. Cancer 1999;85:2103-2113.

20. Jaguar GC, Prado JD, Nishimoto IN, Pinheiro MC, Castro DO, Perez DEC, et al.. Low-energy laser therapy for prevention of oral mucositis in hematopoietic stem cell transplantation. Oral Dis 2007;13:538-543. 